\title{
Diabetic Retinopathy: Understanding Pathologic Angiogenesis and Explor- ing its Treatment Options
}

\author{
Manuel Falcão* ${ }^{* 1,2}$, Fernando Falcão-Reis ${ }^{1,2}$ and Amândio Rocha-Sousa ${ }^{2,3}$
}

\author{
Department of Ophthalmology, Faculty of Medicine, University of Porto Foundation; Portugal; ${ }^{2}$ Department of Oph- \\ thalmology, Hospital São João, Porto, Portugal; ${ }^{3}$ Department of Physiology, Faculty of Medicine, University of Porto \\ Foundation, Portugal
}

\begin{abstract}
Diabetic retinopathy is the major cause of blindness at working age. The pathogenesis behind visual loss is related with retinal angiogenesis and increased retinal vascular permeability. These changes seem to be the result of chronic hyperglycemia and hypoxia. Several mechanisms have been proposed to cause the retinal and vasculature cellular damage. They include the formation of advanced end glycation products, aldose reductase activity and reactive oxygen species. Ultimately, they lead to the expression of VEGF-A. This growth factor seems to play the pivotal role in the development of the complications associated with the disease including break down of the inner blood retinal barrier, macular edema and vasoproliferation. Other mechanisms like inflammation, protein kinase $\mathrm{C}$ activity and erythropoietin have been strongly associated with the pathogenesis.

Laser therapy is still the standard of care for diabetic retinopathy and prevents severe vision loss in $95 \%$ of patients if timely treatment is performed. The better understanding of the disease has led to the production of new management options that may become important adjuvants for the disease. They include intravitreal anti-VEGF therapy, intravitreal steroid therapy and systemic protein kinase $\mathrm{C}$ inhibitors. Vitrectomy is an important option for advanced cases of the disease such as tractional retinal detachment or non-absorbing vitreous hemorrhages.
\end{abstract}

Keywords: Angiogenesis, proliferative diabetic retinopathy, diabetic macular edema, intravitreal anti-VEGF therapy, intravitreal corticosteroid therapy.

\section{INTRODUCTION}

Diabetic retinopathy is a major microvascular complication of diabetes mellitus. Its pathogenesis is heavily related with angiogenesis and vascular permeability induced by hypoxic stimuli and chronic hyperglycemia. It is the leading cause of blindness in patients between 40 and 60 years of age in industrialized countries [1] and is therefore a major health problem, incapacitating people at working age. It affects both patients with type 1 and type 2 diabetes [2-4].

Diabetic retinopathy is a progressive disease that evolves through several different stages asymptomatically before affecting visual acuity. Even in some cases of advanced disease and a poor prognosis if left untreated, visual symptoms may be absent. However, severe visual loss can be prevented in over $90 \%$ of patients if timely diagnosis and proper treatment with retinal laser is performed [5]. Prevention of diabetes mellitus and good metabolic control are cornerstones for avoiding diabetic retinopathy and slowing down its progression $[6,7]$. However, the absence of symptoms in the early stage of disease may lead to late referral to an ophthalmologist with devastating results in vision. Better understanding of the pathogenesis of the disease has allowed recent advances in management options for patients. New treatment

*Address correspondence to this author at the Department of Ophthalmology, Hospital São João, Faculty of Medicine of the University of Porto, Al. Prof. Hernâni Monteiro, 4200-319 Porto, Portugal;

Tel/Fax: 00351 225513669; E-mail: falcao@med.up.pt modalities are being used to treat diabetic retinopathy with promising results [8-18].

\section{Epidemiology}

Diabetes mellitus is a growing major health concern worldwide. In the year 2000,171 million people $(2.4 \%$ of the world's population) were estimated to suffer from this condition. The prevalence is expected to increase to $4.4 \%$ by the year 2030 [19].

Diabetic retinopathy is a progressive disease. Epidemiologic studies in 1984 showed that in patients with type 1 diabetes, some form of diabetic retinopathy was seen in almost every patient after 20 years of disease [3]. In patients with type 2 diabetes mellitus, 80 percent of patients had evidence of disease after this time period [2]. Proliferative diabetic retinopathy can be present in $50 \%$ of patients with type 1 diabetes after 15 years of diagnosis. In type 2 diabetes, these numbers were $5-10 \%$ in patients not treated with insulin and $30 \%$ for patients treated with insulin. These numbers evidently show that the vast majority of diabetic patients will have some form of diabetic retinopathy as long as their lifespan is long enough. Also, an important proportion of patients will reach the advanced stages of the disease. Great attention must be put into screening and rapidly diagnosing these patients so timely diagnosis and therapy can be achieved.

In type 1 diabetes, diabetic retinopathy does not develop until 3-5 years after the onset of the disease [3]. This demon- 
strates that chronic (and not acute), long-lasting hyperglycemia is necessary for the development of retinal disease. $\mathrm{Pa}$ tients with type 1 diabetes do not need immediate screening at the time of diagnosis; this can be postponed for 3-5 years. Type 2 diabetes mellitus has a more insidious onset. It is possible for a patient to have diabetes mellitus for several years and not be aware of that fact. As a result, it is possible that at the time of diagnosis of the systemic disease, diabetic retinopathy may already be present. In some cases, the diagnosis of systemic diabetes mellitus is inferred from the presence of advanced diabetic retinopathy. Patients with newly diagnosed type 2 diabetes should be screened for retinopathy at time of diagnosis. Delayed screening postpones diagnosis and treatment. Treatment is more effective if applied at an appropriate stage of the disease [5]. Several different screening options have been proposed for diabetic retinopathy depending on the grade and severity of the retinal disease. Different methods include retinographies and telemedicine [2022].

\section{CLINICAL FEATURES}

To better understand the pathogenesis of diabetic retinopathy it is important to know the gross clinical features of disease progression.

The disease is clinically classified into non-proliferative or proliferative forms. The non-proliferative lesions occur in the initial phases [23]. As the disease progresses, a proliferative stage develops when new retinal vessels proliferate from existing vasculature (angiogenesis). The visual prognosis of proliferative diabetic retinopathy without treatment is dismal. However, with proper treatment, risk of severe visual loss may be reduced by $50 \%$ [24].

The initial lesions seen in patients with diabetic retinopathy are microaneurysms, small dilations of the retinal capillaries. Later, small areas of hemorrhage within the retina can be seen; as disease progresses areas of necrosis of the retinal nerve fiber layer (cotton wool spots) are observed. As the areas of hypoxia increase, venous dilations, venous loops and intraretinal microvascular abnormalities (IRMA) develop. These features are the hallmark of the nonproliferative disease. Non-proliferative diabetic retinopathy is classified into mild, moderate or severe depending on the number and type of lesions observed [23]. Mild diabetic retinopathy occurs when only microaneurysms are present. Severe non-proliferative diabetic retinopathy occurs when any one of these three parameters is detected in ophthalmic fundus examination: more than 20 intraretinal hemorrhages in each of 4 quadrants; venous beading in 2 quadrants; prominent intraretinal microvascular abnormality in 1 quadrant and no signs of proliferative retinopathy. Moderate diabetic retinopathy occurs when more than microaneurysms are present but none of the "severe characteristics" are observed [23].

Usually, lesions of non-proliferative diabetic retinopathy do not have visual significance and the patient remains asymptomatic. This can occur even in the severe stage of the non-proliferative disease. However, the overall prognosis worsens as the disease progresses. More advanced stages of non-proliferative diabetic retinopathy have a greater risk of becoming proliferative disease.

In diabetic retinopathy vision loss occurs due to two major retinal problems: macular edema (caused by increased vascular permeability) and retinal neovascularization (caused by angiogenesis) [25]; the existence of neovascularization marks the beginning of proliferative disease. Vision loss caused by diabetic retinopathy can be potentially irreversible.

Macular edema is the most frequent cause of moderate visual loss in diabetic retinopathy. It is more common in type 2 diabetes mellitus patients taking insulin than on type 1 patients [4].

Macular edema can exist with or without proliferative diabetic retinopathy and their severities are not directly related. Severe cases of diabetic macular edema can occur in patients with moderate non-proliferative diabetic retinopathy and severe proliferative disease can occur without macular edema [26].

The macula is located in the posterior pole of the eye. Its centre, the fovea, is responsible for central visual acuity. It is an area that physiologically has very little extra-cellular fluid so that minimal diffraction occurs as light traverses the retinal tissue before reaching the photoreceptors [27]. As the disease progresses, a break-down in the blood retinal barrier occurs [28-32] causing an increase in macular vascular permeability and extravasation of plasma from blood [27, 30, 31]. Resorption of the fluid elements from the extracellular space will leave lipoproteins deposit in the outer retinal layers [30]; these can be seen ophthalmoscopically as hard exudates. When the leakage of plasma from small macular vessels is overwhelming, accumulation of extra-cellular fluid occurs. This edema can either affect focal areas of the retina or it can diffuse throughout the posterior pole. In focal edema, leaking microaneurisms are though to cause retinal thickening. A circinate ring of hard exudates commonly surrounds these exudating microaneurisms [30]. In severe cases of diabetic macular edema, intraretinal leakage can occur from dilated retinal capillary bed or from intra-retinal microvascular abnormalities [32]. When the foveal area is affected the patient usually reports blurry vision.

In proliferative diabetic retinopathy the formation of new blood vessels occurs from existing capillaries as a result of angiogenesis. These blood vessels usually arise in the interface between perfused and non-perfused areas of the retina in retinal neovascularization [25]. They can also originate from the optic disk (neovascularization of the disk). These new vessels are extremely immature, fragile, permeable and bleed very easily. By themselves, they do not cause visual compromise, but they are in the origin of severe complications such as vitreous hemorrhage or tractional retinal detachment.

When the retinal blood vessels proliferate, they may grow outside of the retinal plane onto the vitreous body; the vitreous acts as a scaffold for proliferating retinal vessels and fibrous tissue. New vessels reach the vitreous by invading the internal limiting membrane [33].

As a result of the break-down of the blood-retinal barrier, fibronectin, accumulates at the vitreoretinal interface [34]. Fibronectin mediates the migration of endothelial cells favouring vessel growth towards the vitreous cavity [35].

When a fibrovascular component that has grown onto vitreous contracts, traction on the underlying retina can cause tractional retinal detachments. Severe vision loss can occur 
when the central macula is detached. Tractional forces on the fragile immature, proliferating vessels may cause bleeding into the vitreous cavity. Vitreous hemorrhage prevents light from reaching the retina and causes a sudden decrease in visual acuity.

Even in patients who receive adequate treatment, permanent significant visual loss may occur. The ETDRS report number 24 showed that in treated eyes, complications associated with proliferative diabetic retinopathy (vitreous or preretinal hemorrhage and retinal detachment) were more frequently responsible for this end stage disease than macular edema [36].

If no treatment is performed in the proliferative stage of the disease, neovascularization will progress into the anterior segment of the eye, initially on the iris (rubeosis iris) and later on the iridocorneal angle. The new vessels can obstruct the angle or cause close the angle when the fibrovascular tissue contracts. Angle closure blocks aqueous humor drainage. This may substantially increase intra-ocular pressure (neovascular glaucoma). Neovascular glaucoma carries not only a dismal visual prognosis and but it may also be associated with severe ocular pain. The various management options for treatment of neovascular glaucoma are outside the scope of this paper. They include palliative ophthalmic measures to reduce intra-ocular pressure and pain, blockage of vascular endothelial growth factor (VEGF)-A using antiVEGF drugs [37] and, in some cases, enucleation must be the end line option [38-40].

\section{PATHOGENESIS}

As explained above, the main causes of vision loss in diabetic retinopathy are related to angiogenesis and increased vascular permeability. Increased vascular permeability is one of the first stages in both physiological and pathological angiogenesis [41], showing a close interaction between the two pathologic processes. The mechanisms by which diabetes mellitus induces the vascular retinopathy are complex and not completely established. They involve the interaction and balance between angiogenic factors such as VEGF and antiangiogenic factors such as pigment epithelium derived growth factor (PEDF).

The retina is the most metabolically active tissue of the human body, needing high oxygen concentrations. It is very sensible to hypoxia, responding to this noxious stimulus by producing cytokines and growth factors. Physiologically, retinal capillaries are composed of non-fenestrated endothelial cells with tight-junctions and low permeability. There is a high proportion of pericytes surrounding endothelial cells. Pericytes regulate blood flow through the retinal capillaries due to their contractile structure. These cell types, along with other retinal cells (Müller cells and astrocytes) form the inner blood-retinal barrier [11]. Like the blood-brain barrier, this barrier is fundamental for the maintenance of retinal homeostasis as it prevents the leakage of macromolecules into retinal tissues.

The outer blood-retinal barrier occurs between the tight junctions of the cells of the retinal pigment epithelium. It is also fundamental for ocular homeostasis; its disruption is associated with other angiogenic ocular disease such as wet age-related macular degeneration. The outer blood-retinal barrier has no role in the pathogenesis of diabetic retinopathy.

The major driving factors in the etiology of diabetic retinopathy are related to persistent hyperglycemia and hypoxia. Many early changes in endothelial vascular cells are hyperglycemia-induced, and include hemodynamic alterations, endothelial dysfunction, inflammation, and changes in the expression of growth factors. Hyperglicemia-induced changes are consequence of formation of advanced glycation end (AGE) products, sorbitol and reactive oxygen species. AGE products are a reflex of prolonged hyperglycemia and have been correlated with the onset and severity of diabetic retinopathy in animal models [42]. AGE result from nonenzymatic glycation of proteins. Cell damage may occur as a result of malfunction of a wide variety of intracellular and extracellular proteins [43]. AGEs have been linked with the production of reactive oxygen species, vascular leakage and VEGF production [44].

Aldose reductase is an enzyme that reduces glucose to sorbitol in hyperglycemic states. Because the oxidation of sorbitol into fructose is a slower reaction, accumulation of sorbitol occurs inside the cell. This may lead to osmotic cellular damage $[43,45]$ and endothelial dysfunction.

Reactive oxygen species have also been associated with diabetic microvascular abnormalities. Normal mitochondrial glucose phosphorylation releases reactive oxygen species that oxidize proteins and cellular membranes. This production is increased in hyperglycemic states. Also, autooxidation of glucose can occur creating more free radicals inducing further cellular and protein damage. This increased oxidative stress reduces nitric oxide levels [43], promotes leukostasis and may disturb the inner retinal blood barrier $[11,46,47]$. Oxidative stress can lead to the production of VEGF[47]. All these factors contribute to the development of the retinopathy.

One of the first and most specific retinal changes induced by hyperglycemia is the death of microvascular contractile cells (pericytes). Pericyte death occurs through hyperglycemia triggered apoptosis [48]. Normal pericytes contain large amounts of actin and surround capillary endothelial cells. They have a contractile function that regulates capillary blood flow. Other functions such as maintenance of capillary structure and inhibition of endothelial cell proliferation have been described [11]. The death of pericytes and the loss of vascular intercellular contacts may predispose to endothelial cell proliferation, facilitating the development of microaneurysms, small dilations of the retinal capillaries that can be seen ophthalmoscopically. They are the initial lesions to be seen in diabetic retinopathy. Loss of pericytes will eventually lead to apoptosis of capillary endothelial cells and the complete loss of cellular elements from the retinal vasculature. This renders the capillary remnants non-functional, meaning that the areas of retina supplied by these capillaries are no longer irrigated. This is known as capillary closure.

Another initial change seen in diabetic retinopathy is an increase in the capillary basement membrane thickness. This increase in thickness occurs in other ocular basement membranes. It may be associated with the deposition of advanced glycation end products and to abnormal production of basement membrane material. Its relationship to the diabetic reti- 
nopathy cascade is not totally clear $[11,49]$. However, like the loss of pericytes, increased basement membrane thickening is thought to contribute to capillary closure [11], increasing ischemic areas. Areas of ischemia often correlate ophthalmoscopically with hemorrhage and cotton wool spots. Fig. (1) summarizes the pathophysiology of diabetic retinopathy.

\section{ROLE OF HUMORAL FACTORS (HIF1- $\alpha$; VEGF; PDGF) IN DIABETIC RETINOPATHY PATHOGENE- SIS}

Retinal cells have a high oxygen demand. The hypoxia resulting from the previously described microvascular alterations is a stimulus for the production of a variety of growth factors. Hypoxia up-regulates the cellular production of hypoxia inducible factor $1-\alpha$ (HIF1- $\alpha$ ), a molecule important for cellular viability in hypoxic states [50]. This factor stimulates the production of VEGF and nitric oxide; both will induce vasodilation, while VEGF will also increase vascular permeability and promote angiogenesis [11].

VEGF-A is the better studied of a family of molecules that include VEGF-A, -B, -C, -D, -E and placental growth factor, being referred throughout the paper as VEGF. This peptide has several isoforms; isoform VEGF165 is the most abundant and potent of all. VEGF is both a powerful angiogenic and a powerful permeability factor. In angiogenesis it acts as a proliferation, migration and survival factor for endothelial cells [51]. As a permeability factor, it is 50000 times more potent than histamine in inducing cutaneous mi- crovascular permeability increase [52]. VEGF binds to endothelial cell receptors with tyrosine kinase activity [53, 54]. Three types of membrane bound VEGF receptors have been described: VEGFR 1, VEGFR 2 and VEGFR 3 with different functions and place of action. VEGFR 1 is expressed constitutively on retinal microvessels with both angiogenic and anti-angiogenic properties [53]. VEGFR 3 mediates angiogenic effects of lymphatic vessels [53].

The primary mediator of the angiogenic, proliferative and vasogenic effects of VEGF is the receptor VEGFR2. Its retinal expression is induced by the presence of VEGF and it is increased in the microvessels of retinas with diabetic retinopathy [55], being this change in the type of VEGFR expression found in the late stages of the disease in areas with established microvascular leakage [56]. Finally another type of VEGF receptor has been described, a non-membrane bound VEGFR 1 (sFlt-1). It acts as scavenger for soluble VEGF, blocking its activity. It is present in the cornea and is an important factor in preventing corneal angiogenesis [57].

VEGF is produced by several retinal cells including, retinal pigment epithelial cells, Müller cells, endothelial cells and pericytes [58] in response to stimuli such as hypoxia and advanced glycation end products. It can be detected in the retina of diabetic patients even before the development of neovascularization [59]. However, due to its potent angiogenic and vasogenic characteristics, its expression is greater in cases of retinal and choroidal neovascularization and in patients with "severe" diabetic macular edema [57, 60, 61].

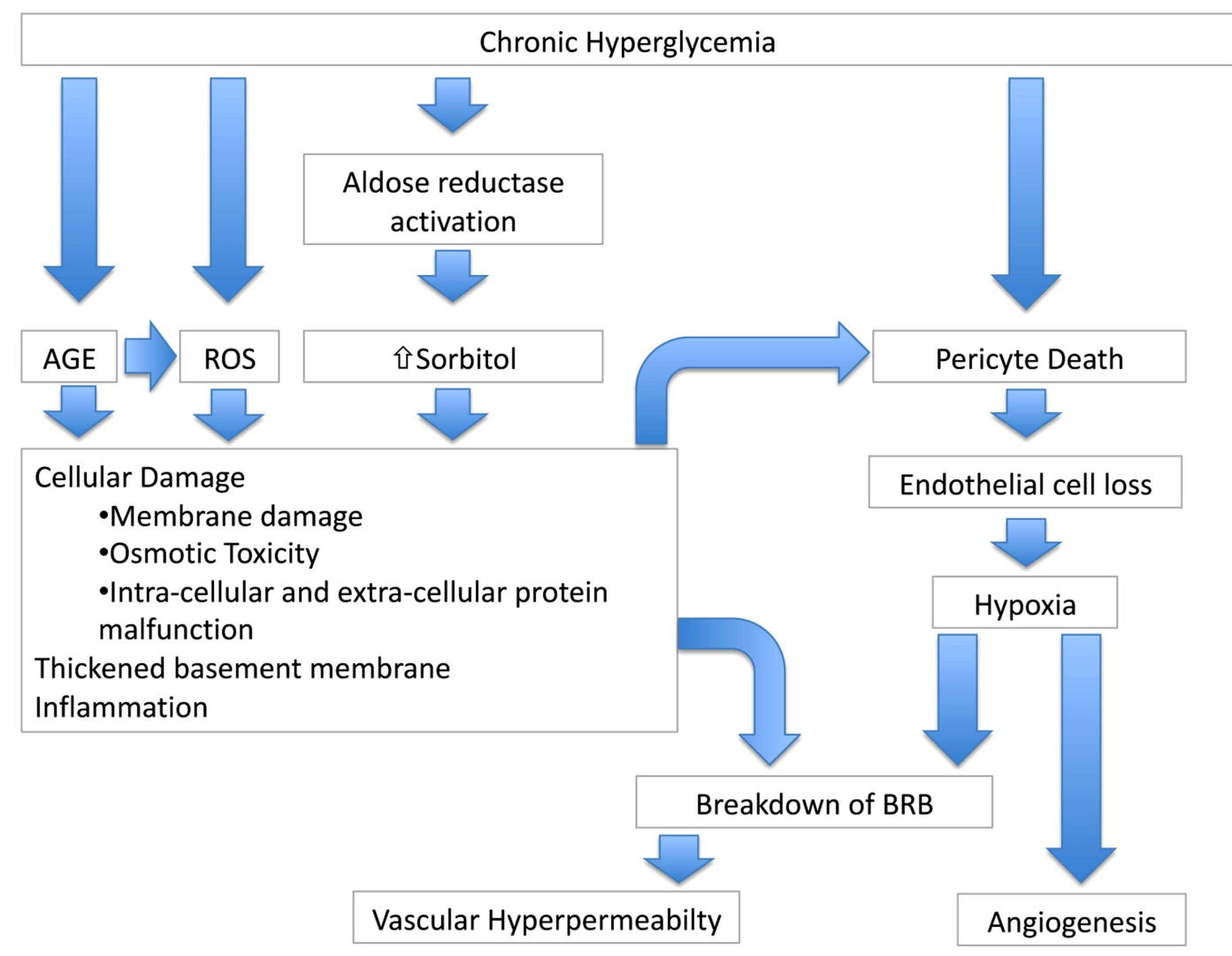

Fig. (1). Pathogenesis of diabetic retinopathy. Schematic overview of the effects of chronic hyperglycemia and its implications in cellular damage. AGE: Advanced Glycation End Products. ROS: Reactive Oxygen Species. BRB: Blood Retinal Barrier. 
Even though other factors such as protein kinase $\mathrm{C}$ and erythropoietin have been linked to the pathogenesis of diabetic retinopathy, VEGF plays a central role [62, 63].

VEGF reduces the expression of occludin, an important protein for the preservation of the endothelial tight junctions [11] and consequently for the preservation of the blood retinal barrier. VEGF has also been shown to cause the breakdown of the blood retinal barrier and promote vascular leakage [64]. On the other hand, inhibition of VEGF production reduces capillary vascular leakage [65].

The administration of VEGF165 into the vitreous of healthy non-human primates resulted in the formation of several of the manifestations of diabetic retinopathy including microaneurysms, hemorrhage, capillary closure, vascular leakage and retinal neovascularization; inhibition of this injected VEGF prevented the formation of these complications [66-69]. VEGF is elevated in the intra-ocular fluids of patients with diabetic retinopathy; these levels declined after successful laser therapy [54, 70].

It seems that VEGF alone can reproduce most of the manifestations of diabetic retinopathy and high levels of VEGF are present in eyes with diabetic retinopathy. Preventing VEGF formation or inhibiting the one that is present is therefore a corner stone for effective treatment. This rational has lead to the development of new therapies to better control the pathologic VEGF levels that are observed in this disease.

In physiologic conditions, retinal Müller cells produce PEDF. It is present in the normal vitreous cavity and may play an important part in preventing ocular neovascularization in physiologic conditions [71]. PEDF is a potent inhibitor of angiogenesis that has been shown to reduce VEGF and erythropoietin induced endothelial cell proliferation [72]. PEDF antagonizes VEGF action [73] in mice retinal neovascularization models. However, in hypoxic states, the production of PEDF is reduced; therefore VEGF action is not inhibited by this growth factor.

In a study by Patel et al. human eyes with diabetic retinopathy were found to have increased vitreous concentrations of VEGF and lower concentrations of PEDF and sFlt-1 when compared with patients with macular holes (a nonangiogenic macular disease) [70]. This confirms the balance of this disease towards pathologic angiogenesis. The role of HIF-1, VEGF and PEDF in diabetic retinopathy is illustrated in Fig. (2).

\section{ROLE OF INFLAMMATION IN DIABETIC RETI- NOPATHY PATHOPHYSIOLOGY}

Inflammation has also been linked to the pathogenesis of diabetic retinopathy. Many of the features of diabetic retinopathy are closely linked to inflammatory processes such as tissue edema, increased blood flow and the migration of inflammatory cells. Hypoxia is known to cause up-regulation of various inflammatory mediators [74]. VEGF is also an inflammatory mediator that increases vascular permeability and induces the expression of intracellular cellular adhesion molecule-1 (ICAM-1) and vascular cell adhesion molecule-1 (VCAM-1) [75]. Both molecules are responsible for the chemoatrraction of leukocytes into the vascular walls and their migration into tissues [76]. Leukocytes promote disrup- tion of inner retinal barrier as well as angiogenesis [74]; they also contribute to the permeability and angiogenic cascade by producing VEGF.

In patients with diabetic retinopathy, increased number of neutrophils have been observed in capillary walls [77]. These phenomena result in injury to endothelial cells and increased vascular permeability [78], with consequent edema.

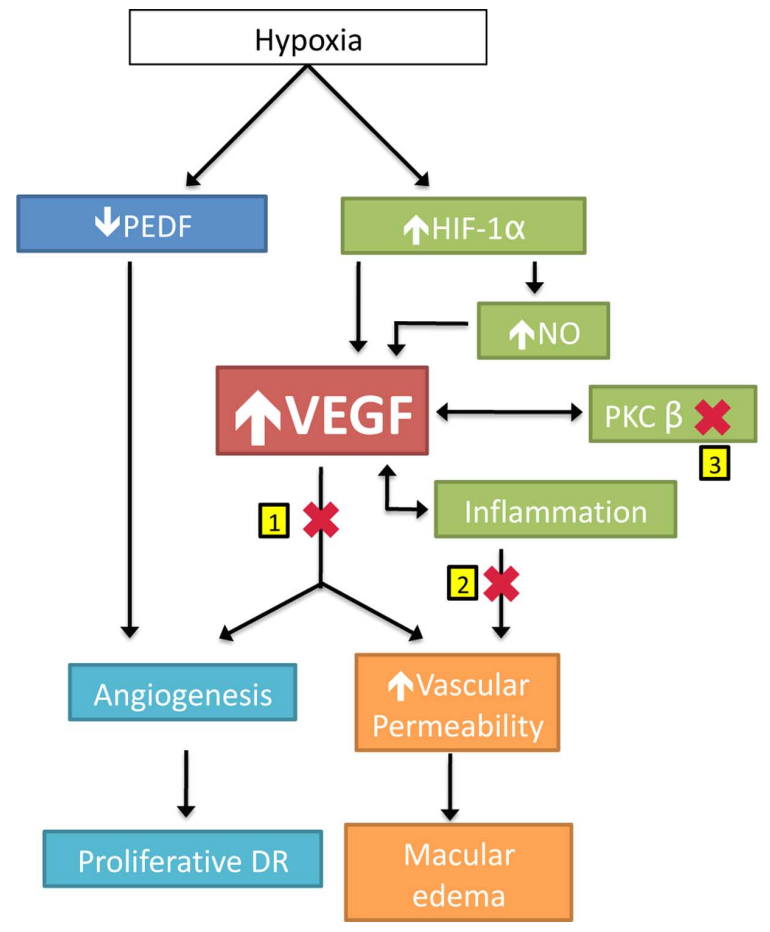

Fig. (2). Central role of hypoxia and VEGF in the pathogenesis of diabetic retinopathy. The crosses represent points in the pathologic cascade where available pharmacologic therapy acts. 1: anti-VEGF drugs; 2: corticosteroids; 3: PKC- $\beta$ inhibitors. See Table 1. VEGF: Vascular endothelial growth factor. PEDF: Pigment epithelium derived growth factor. HIF-1 $\alpha$ : Hypoxia inducible factor- $1 \alpha$; PKC$\beta$ : protein kinase $\mathrm{C}-\beta$.

Monocytes also appear to be important cells in proliferative diabetic retinopathy as they have been identified in neovascular tufts. Their inhibition results in decrease of the pathological neovascular activity [74]. Inhibiting the inflammatory pathway and the migration of leukocytes is another appealing treatment option for diabetic retinopathy.

\section{Protein Kinase C}

In vascular cells, hyperglycemia induces also the synthesis of diacylglycerol (DAG) from membrane inositides. This promotes the activation of protein kinase $\mathrm{C}$ (PKC). The PKC family is a family of enzymes with several isoforms [79]. PKC- $\beta$ may play an important role as it has been shown to reduce VEGF induced hyperpermeability [80]. Hyperglycemia therefore induces PKC activity in endothelial cells involving this mechanism in the pathologic effects [81]. Vascular effects include increased permeability and cellular proliferation. PKC actions are mediated by various growth factors [81]. PKC is activated by VEGF and it may mediate the potent vascular actions of the latter; the PKC intra-ocular level rise after VEGF injection. On the other hand, PKC also 
Table 1. Summary of the Pharmacologic Therapies Available for the Treatment of Diabetic Retinopathy; The Place of Action of Each Drug in the Pathogenesis Cascade is Illustrated in Fig. (2)

\begin{tabular}{|c|c|c|c|c|c|}
\hline Anti-VEGF & $\begin{array}{l}\text { Pegaptanib, Ra- } \\
\text { nibizumab, } \\
\text { Bevacizumab }\end{array}$ & $\begin{array}{l}\text { Neutralization of } \\
\text { intra-ocular VEGF } \\
\text { molecules (1) }\end{array}$ & Intravitreous & $\begin{array}{l}\text { Rapid regression of } \\
\text { neovascular vessels; } \\
\text { Rapid decrease in macular } \\
\text { edema; stops intra-ocular } \\
\text { bleeding by "shutting } \\
\text { down" immature vessels }\end{array}$ & $\begin{array}{l}\text { Intra-ocular administration has risk of } \\
\text { endophthalmitis. No action on the } \\
\text { production of VEGF and retreatments } \\
\text { are frequent; no action on the patho- } \\
\text { genesis of the disease; may precipitate } \\
\text { tractional retinal detachment or retinal } \\
\text { tears }\end{array}$ \\
\hline $\begin{array}{l}\text { Corticoster- } \\
\text { oids }\end{array}$ & $\begin{array}{l}\text { Triamcinolone } \\
\text { Fluocinolone }\end{array}$ & $\begin{array}{l}\text { Potent inhibition of } \\
\text { inflammation and } \\
\text { vascular leakage (2) }\end{array}$ & Intravitreous & $\begin{array}{l}\text { Reduces vascular leakage } \\
\text { and macular edema. } \\
\text { Triamcinolone's action } \\
\text { can last up to six months. } \\
\text { Fluocinolone is being } \\
\text { studied in sustained re- } \\
\text { lease formulations; it is a } \\
\text { less potent steroid, may } \\
\text { have lower side effects. }\end{array}$ & $\begin{array}{l}\text { Intra-ocular administration has risk of } \\
\text { endophthalmitis. } \\
\text { Has no action on the pathogenesis of } \\
\text { the disease, patients frequently need } \\
\text { retreatments. High risk of cataract, } \\
\text { ocular hypertension and glaucoma. }\end{array}$ \\
\hline Anti-PKC $\beta$ & Ruboxistaurin & $\begin{array}{l}\text { Inhibition of intra- } \\
\text { cellular PKC } \beta \text { ( } 3 \text { ) }\end{array}$ & Oral & $\begin{array}{l}\text { Slows the progression of } \\
\text { diabetic retinopathy }\end{array}$ & $\begin{array}{l}\text { No action on advanced stages of the } \\
\text { disease such as macular edema or } \\
\text { retinal neovascularization }\end{array}$ \\
\hline
\end{tabular}

induces VEGF expression [82]; finally, the PKC inhibitors have been shown to inhibit VEGF effect [80].

\section{ERYTHROPOIETIN}

Erythropoietin is a glycoprotein with proliferative, migratory and angiogenic actions initially identified in the kidney [83]. Its expression, like VEGF expression, is ischemia induced. Its levels are increased in the vitreous of patients with proliferative diabetic retinopathy and diabetic macular edema [84]. However, its actions on angiogenic vascular proliferation seem to be independent of VEGF activity [83, 85]. The role of erythropoietin in diabetic retinopathy has raised other important issues. Patients with diabetic retinopathy frequently have nephropathy and chronic renal failure, and synthetic erythropoietin has been used to treat anemia in end stage renal disease. However, the effects that synthetic erythropoietin can have on the progression of diabetic retinopathy has not been completely established. Some authors defend that administration of erythropoietin increases the risk of proliferative retinopathy $[86,87]$. Even so, in a mouse model of retinopathy, a protective effect of erythropoietin has been described [88]. This widens the options for developing future therapies.

\section{SYSTEMIC FACTORS}

Diabetes mellitus is a systemic disease affecting many end organs. Not surprisingly, several systemic factors have been found to have an important association with the development and progression of the retinal disease. The levels of metabolic control (level of hyperglycemia, total time of diabetes mellitus), arterial hypertension and dyslipidemia have been shown to worsen diabetic retinopathy.

\section{METABOLIC CONTROL}

The duration of diabetes mellitus is one of the major factors for the development of retinopathy. In type 1 diabetes, the disease does not appear until 3-5 years after diagnosis. The probability of developing disease is proportional to its duration. However, several studies have demonstrated that a tight glycemic control is also important for preventing and delaying the progression of diabetic retinopathy [6]. There is a direct relationship between glycated hemoglobin levels (HbA1C), a marker of the average glycemic level of a patient during the last month, and the incidence of the retinal disease. This was demonstrated in the Diabetes Control and Complication Trial (DCCT) [6] that compared diabetic retinopathy in two type 1 diabetes groups. The first group was subjected to intensive therapy to control blood glucose levels; while the second was treated by conventional therapy. Tight control of blood glucose showed a decrease in development and progression of diabetic retinopathy after six years. Importantly, it also showed beneficial results in diabetic nephropathy and neuropathy.

The protective effect on retinopathy also showed long term differences. Some of the patients of both groups of the DCCT cohort were later placed on intensive therapy. After 10 years of $\mathrm{Hb} 1 \mathrm{Ac}$ at similar levels in both groups, patients with previous intensive therapy had significant lower retinopathy progression and a lower proportion of proliferative retinopathy cases [89].

In the UK Prospective Diabetes Study (UKPDS)[7], type 2 diabetes patients were either randomized to conventional therapy or intensive control. Over 10 years of follow up, it was demonstrated that patients on the intensive therapy arm fared better not only in terms of ocular manifestations but in 
many other important complications of diabetes such as sudden death, myocardial infarction, heart failure, stroke and nephropathy. These observations highlight the overall importance of a good metabolic control. It is important for the prevention and delaying of ocular disease and fundamental for the diabetic patient as an individual.

Interestingly, both the UKPDS and the DCCT showed that a sudden improvement in glucose levels might provoke an unexplained transient increase in background diabetic retinopathy. However, these changes are reversible with time and should not deter the medical team from seeking an adequate glycemic control [90].

\section{ARTERIAL HYPERTENSION}

Arterial hypertension has been shown to be an independent risk factor for the development and progression of diabetic retinopathy. Increased arterial blood pressure may cause further endothelial damage on an already diseased vascular bed, and may increase the levels of VEGF and promote the permeability and angiogenic cascades.

Hypertension control in patients with type 2 diabetes has been shown to help prevent retinopathy and other microvascular complications [91]. Patients with tight blood pressure control have a significant lower reduction in risk of retinal photocoagulation and vision loss when compared to conventional blood pressure control patients [92]. There was also a decrease in other evaluated endpoints such as risk of nephropathy, stroke, myocardial infarction and death. For ocular and systemic reasons, it is mandatory for patients to have both a good metabolic control and blood pressure within normal limits. Lowering blood pressure in normotensive diabetic patients has also been linked to decreased progression of diabetic retinopathy [93].

\section{DYSLIPIDEMIA}

The true clinical importance of dyslipidemia in diabetic retinopathy has not been, until now, completely established. However, abnormal serum lipids have been linked to the development of hard exudates in diabetic retinopathy [94]. It was also demonstrated that in patients with type 1 diabetes, the severity of the retinopathy was positively correlated with high triglyceride levels [95]. The use of fenofibrate in patients with diabetic retinopathy slows the progression of a prior retinopathy, when compared to placebo [96]. However the plasma lipid levels did not influence these results. So, this protective effect seems to be independent of the lipid plasma profile.

\section{TREATMENT}

The better understanding of the pathogenesis of diabetic retinopathy has led to the new treatment options for this disease. However, it cannot be over stressed that primary prevention of diabetic retinopathy and early diagnosis are fundamental keys for controlling the disease. They are the cornerstone of management.

Not all stages of diabetic retinopathy require prompt medical action. For the earlier stages of non-proliferative diabetic retinopathy no treatment is warranted. These patients should be periodically monitored. If there is no progression of the disease, then there is no need for local treat- ment. The main goal to achieve in this population is metabolic and arterial blood pressure control.

Specific treatment options for diabetic retinopathy include retinal laser therapy (photocoagulation), intravitreal anti-VEGF therapy, intravitreal corticosteroids and oral protein kinase $\mathrm{C}$ inhibitors administration. Other pharmacotherapies such as anti-platelet agents have not shown benefits in clinical trials [5, 97].

\section{LASER THERAPY}

Laser therapy of diabetic retinopathy consists of placing small laser burns on the retina causing photocoagulation and death of retinal tissue. Usually they target diseased retinal tissue that produces the growth factors responsible for diabetic retinopathy. Even though it is a 30 year-old destructive approach, it is still the mainstay of treatment for the disease. Two different modalities exist: pan retinal photocoagulation (PRP) for proliferative retinopathy and focal/grid laser therapy for macula edema.

PRP consists of laser burns on the mid periphery of the retina in $360^{\circ}$. The central macular area is spared to preserve visual acuity. The laser burns can be made throughout several sessions. The size of the laser spots may vary from 50$500 \mu \mathrm{m}$. It is an outpatient procedure that is usually performed at a slit-lamp. Theoretically, the laser burns destroy peripheral ischemic retina and improve perfusion of the remaining tissues, reducing ischemia. Consequently, a decrease of growth factor (including VEGF) production occurs with consequent loss of vasogenic and vasoproliferative stimuli. A decrease in ocular VEGF levels has been described after PRP.

In the Diabetic Retinopathy Study, there was a $50 \%$ decrease in severe visual loss in patients with proliferative diabetic retinopathy that were treated with PRP. It showed the efficacy of this treatment modality even in advanced stages of the disease [24]. With PRP, regression of the neovascular tufts can occur. This diminishes the risk for vitreous hemorrhage and tractional retinal detachments. However, even treated, many patients can progress to severe visual loss.

Currently, PRP is recommended for proliferative diabetic retinopathy and for selected cases of severe non-proliferative diabetic retinopathy [98]. The ETDRS trial does not recommend PRP in eyes with mild or moderate nonproliferative diabetic retinopathy [5]. Stress should be placed on metabolic and arterial blood pressure control and frequent ophthalmologic follow-up should occur so laser treatment can be started promptly if disease progresses.

Laser therapy can also be used for the treatment of diabetic macular edema. Focal laser spots are delivered to areas of increased vascular permeability in the retina; these areas may be localized foci of leaking microaneurysms. The other treatment modality is performed when the macular edema is diffuse. A laser grid is done on the macula. Care should be taken to avoid the fovea (center of the macular area), the point where visual acuity is highest. A laser burn in the fovea may cause an irreversible central scotoma. The effectiveness of laser therapy for macular edema has been demonstrated in the ETDRS trial. The rationale for treatment is similar to the rational for proliferative diabetic retinopathy: destruction of diseased retinal tissue to allow better perfusion of healthier 
areas and diminish the production of noxious growth factors. The ETDRS trial showed that for eyes with macular edema, focal photocoagulation is effective in reducing the risk of moderate visual loss [5].

Laser therapy is not innocuous. PRP destroys areas of the retina and causes visual field constriction, night blindness and color vision loss. Also, PRP performed when macular edema is present can worsen the edema; in these cases focal laser therapy should be performed before or with PRP [9, 99]. The possibility of inadvertently photocoagulating the fovea also exists.

In the EDTRS studies, significant vision loss only occurred in $5 \%$ of patients [100]. However, there are several limitations to laser therapy. Even though it prevents severe visual loss in the vast majority of patients, in a large number of patients, it fails to recover visual acuity to normal levels. It is also a destructive procedure with several side effects that interfere with the patients' vision and quality of life. Also, it fails to prevent vision loss in some patients. Whenever a dense vitreous hemorrhage is present, it is impossible to deliver laser treatment to the retina.

At this moment laser therapy is still the benchmark for treatment of diabetic retinopathy. Recently, combining laser treatment with intravitreal anti-VEGF therapy (bevacizumab) has become more frequent $[15,101]$. However, the destructive approach is not satisfactory and the above-mentioned issues must be overcome. This has led to the development of adjunctive therapeutic strategies to maintain visual function at the best possible levels.

\section{ANTI-VEGF THERAPY}

Due to its cornerstone place in the pathogenesis of diabetic retinopathy, the possibility of using anti-VEGF therapy for this disease is a logical approach. As has been previously described, VEGF has important roles in the origin of both macular edema and proliferative retinopathy. Inhibiting the molecule is potentially useful in both sight-threatening conditions of the disease [17]. Intra-ocular VEGF therapy in clinical practice is limited to three different drugs: pegaptanib, ranibizumab and bevacizumab. Currently none of the available anti-VEGF molecules have been approved for the treatment of any stage of diabetic retinopathy.

Pegaptanib is pegylated aptamer with selective antiVEGF-165 activity. Its selectivity distinguishes it from the other anti-VEGF molecules available; ranibizumab and bevacizumab inhibit all VEGF isoforms. It has been approved for intra-ocular treatment in wet age-related macular degeneration; its results were reported in the VISION trials [102]. It has been used off-label for diabetic retinopathy for both macular edema and proliferative disease. Results have been reported in short series and clinical trials [103, 104]. It has shown effectiveness in regression of neovascularization and significant decreases of macular edema. However, these results are relatively short lived and require multiple injections for maintenance of treatment.

Ranibizumab is composed of the Fab fragment of an antibody with enhanced VEGF affinity. It inhibits all VEGF isoforms. Like pegaptanib it has been approved for intraocular use for the treatment of wet age-related macular degeneration. It revolutionized management of wet age-related macular degeneration, as it was the first therapy to demonstrate mean increase in visual acuity in patients with this disease in randomized clinical trials $[105,106]$. It has also been shown very effective in the regression of retinal neovascular disease as well in diabetic macular edema. Like pegaptanib, its effect is also short, requiring multiple injections to maintain its effect $[18,107,108]$.

Unlike the other two molecules, bevacizumab is not approved for intra-ocular use in any condition. It is whole antibody against all VEGF isoforms that was developed for the treatment of metastasized colorectal carcinoma. Its use in oncology has grown to other carcinomas. It has been used intra-ocularly for wet age related macular degeneration with promising results $[109,110]$. In ophthalmology, the use of bevacizumab has grown due to its significant lower price when compared with the previous molecules. Its use in diabetic retinopathy has also grown with promising results in proliferation and macular edema [111-113] and in the clearing of vitreous hemorrhages [114]. It has shown effectiveness in neovascular glaucoma secondary to ischemic retinal diseases including diabetic retinopathy [37].

In comparison with laser therapy, anti-VEGF therapy acts more rapidly in reducing macular edema and in causing the regression of neovascular vessels [112, 114]. Even though anti-VEGF therapy targets the major molecule in diabetic retinopathy pathogenesis, the results with this therapy are not completely satisfying when used alone. AntiVEGF therapy targets existing VEGF and decreases vascular permeability improving diabetic macular edema. In a 24 month long study, intravitreal bevacizumab without laser showed significant decrease of maculae edema and improvement in mean visual and a mean of 5.8 injections per patient [13].

Anti-VEGF therapy also inhibits proliferation, migration and promotes apoptosis of endothelial cells $[115,116]$ and causes rapid regression of retinal neovascular tufts [112, 114]. However, it has no action on hypoxia and on the stimuli that are leading to VEGF production. Also, they have no effect in reversing the effects of hyperglycemia or promoting a better oxygenation of retinal tissues. As noxious stimuli remain present, new VEGF will be continuously produced restarting the pathogenic cascade and demanding a new injection. Anti-VEGF therapy is usually repeated in time intervals from 4 to 6 weeks. Sustained release formulations at this point are not available for these drugs. At this point, it appears that anti-VEGF therapy "buys time" for the patient with diabetic retinopathy by regressing and holding back disease progression until definitive (laser or surgery) treatment can be obtained. This is especially important in situations of vitreous hemorrhage. Even though some authors use intravitreal bevacizumab as the first line agent in selected cases of diabetic retinopathy[113] including diabetic macular edema [13], it is still early to recommend at the moment, anti-VEGF therapy without laser therapy outside clinical trial settings.

Another limitation of intra-ocular anti-VEGF therapy in diabetic patients could be related to systemic side effects [57]. VEGF in the myocardium improves perfusion, collateral circulation and reduces ischemic accidents. Systemic anti-VEGF therapy in cancer patients increased stroke. These facts raise the hypothesis that systemic absorption of intra- 
ocular anti-VEGF may further increase the already high risk of macrovascular complications of diabetes (stroke, and myocardial infarction). Studies have not shown a significant increase in these events, however only further longitudinal studies can definitely settle this issue [117].

\section{CORTICOSTEROIDS}

Inflammation is an important feature of diabetic retinopathy that has been therapeutically investigated. Corticosteroids induce liportin synthesis that inhibits phospholipase A2, preventing the release of arachidonic acid from phospholipids [118]. They act very upstream in the inflammatory cascade and are potent anti-inflammatory drugs. Corticosteroids have been shown to reduce vascular permeability, reduce the breakdown of the blood retinal barrier, inhibit leukocyte adhesion to vascular walls and inhibit VEGF gene transcription and translation [9, 10]. They address various factors in the pathogenesis of diabetic retinopathy, especially complications related to increased vascular permeability. Several different steroids have been used to treat diabetic macular edema: triamcinolone, fluocinolone and dexamethasone. Their rapid action in decreasing macular edema was a promising feature. Like with intravitreal anti-VEGF therapy, the action of corticosteroids is short lived. Frequently, new injections are needed when the anti-edematous effects wanes. This happens at different time intervals depending on the half-life of the steroid used.

Systemic corticosteroids have been associated with ocular complications such as cataract formation, increased intraocular pressure and glaucoma. These side effects also occur with intra-ocular formulations and may be a limit to these procedures.

Triamcinolone is a synthetic corticosteroid used through an intra-ocular injection in different etiologies of macular edema (diabetic, venous occlusive disease, uveitis) [119]. In diabetic macular edema, when compared to macular laser therapy triamcinolone has a faster onset of action. Due to its depot formulation, one single injection can exert is antiinflammatory effect for up to six months. However, for diabetic macular edema, in a randomized clinical trial focal laser therapy was, in the long-term, superior to the triamcinolone injection. Laser therapy also had a significant lower number of adverse effects such as cataract and ocular hypertension [10, 14]. These results re-enforced laser therapy as the mainstay of treatment for diabetic macular edema. However, in some patients with LASER refractory edema, adjunctive therapy with triamcinolone can be an alternative [120].

The need for re-injections has led to the development of sustained release formulations of corticosteroids that can be placed in the vitreous cavity. These slow release formulations avoid the need for repeated injections; theoretically they release smaller amounts of corticosteroids and may cause less secondary effects. There are no sustained-release delivery systems of triamcinolone. Other corticosteroids have been incorporated into these devices. They include dexamethasone and fluocinolone. Dexamethasone implants last from seven to 35 days and are not an optimal solution for diabetic macular edema. Fluocinolone implants can last up to three years, a more appealing time period for treating this chronic condition. One of these implants (Medidurß) is be- ing evaluated for efficacy and safety in diabetic macular edema [118].

\section{Protein Kinase $\mathbf{C}$ inhibitors}

Hyperglycemia activates several isoforms of protein kinase $\mathrm{C}(\mathrm{PKC})$. PKC $\beta$ mediates several ocular complications of diabetes. It is activated by VEGF [121] and is a potential target for therapy of diabetic retinopathy.

An oral PKC $\beta$ inhibitor, ruboxistaurin, has been tested in clinical trials. In one study, patients with diabetic retinopathy were randomized either for oral ruboxistaurin or placebo. The patients treated with ruboxistaurin had a $40 \%$ lower risk of having sustained moderate visual loss, a lower rate of progression of macular disease and a lower need of laser therapy [121]. During a follow up of 36 months, ruboxistaurin slowed the decline in visual acuity associated with diabetic retinopathy, in patients with moderately to very severe non-proliferative diabetic retinopathy [16]. So, PKC $\beta$ inhibitors may be important in slowing down the progression of diabetic retinopathy, however they provide no benefit for patients with established visual loss such as severe macular edema, proliferative diabetic retinopathy and vitreous hemorrhage.

Pharmacologic options for diabetic retinopathy are summarized in Table $\mathbf{1}$.

\section{Vitreo-retinal Surgery}

In very severe cases of proliferative diabetic retinopathy with tractional retinal detachment or non-resolving vitreous hemorrhage, pars plana vitrectomy may become the only effective treatment option. The vitreous provides a scaffold for the growth of fibrovascular proliferations from the retina. The majority of these neovascular membranes adhere to the posterior vitreous cortex. When the fibrovascular component contracts or when traction is exerted by the posterior hyaloid, vitreous hemorrhage or tractional retinal detachments can occur.

Vitrectomy allows the removal of the vitreous and the reduction of tractional forces. One of the goals of vitreous surgery in diabetic retinopathy is the removal of as much vitreous as possible including the posterior hyaloid, the bridge for the fibrovascular growth. It is also possible to use delamination and segmentation techniques to remove fibrovascular membranes that lie on the internal limiting membrane and cause retinal distortion [8, 100, 122, 123]. The removal of these tractional elements may improve the retinal architecture and provide benefits for vision.

Since PRP is the mainstay of treatment for proliferative diabetic retinopathy, vitrectomy is an optimal chance for further laser treatment. Endolaser probes have been developed and laser can be directly applied to the retina during surgery. This allows laser treatment immediately after the clearance of the vitreous hemorrhage.

The availability of the anti-VEGF therapy has changed the approach in many surgical patients with proliferative disease. Its use pre-operatively causes a rapid involution of neovascular tufts and the decrease in intra-operative bleeding; this effect can be seen a few days after treatment. It may also reduce the adherence of the fibrovascular complex to the retina and allow an easier delamination of the pathologic 
membranes. Its use at the end of surgery may reduce the risk of post-operative hemorrhage. The use of bevacizumab has therefore been advocated for many surgical cases [12, 124]. However, the rapid involution of fibrovascular membranes caused by anti-VEGF therapy can cause a rapid increase in vitreous traction precipitating tractional and regmatogenous retinal detachments. This approach should be used with care [12].

Triple therapy (vitrectomy, endolaser and anti-VEGF) is also a valid option.

Vitrectomy with internal limiting membrane peeling for diabetic macular edema has also been studied, however, the improvement in anatomical results did not match improvement in visual acuity. There is no proven benefit for surgery over medical therapies for this condition [125]. Even though surgery can be a sight saving therapy, the visual potential depends on the preoperative and postoperative status of the macula, as well as on retinal perfusion and the health of the optic nerve. Vitrectomy surgery may have intraoperative and postoperative complications, including cataract, anterior hyaloidal fibrovascular proliferation, fibrovascular ingrowth, retinal detachment, and recurrent vitreous hemorrhage.

\section{CONCLUSION}

Diabetic retinopathy is a complication of diabetes that will eventually affect all type 1 diabetes patients and $80 \%$ of type 2 patients. The most important thing in any medical condition is prevention. Primary prevention of type 2 diabetes (the majority of the patients) is fundamental for halting all the complications of diabetes. Once the disease is established, it is known that the time since diagnosis is a major factor for developing retinal disease. However, it has been proven that a good metabolic control confirmed by low levels of $\mathrm{Hb} 1 \mathrm{AC}$, delays the initial manifestations and progression of the disease. Also, the tight control of blood pressure is a very important factor in slowing the progression.

Screening for diabetic retinopathy is important for reducing blindness associated with the disease. The early and moderate stages are asymptomatic, meaning that patients require monitoring so that treatment can be performed timely and prevent visual loss. Diagnosis at late stages may render treatment attempts ineffective with consequent blindness.

VEGF plays a very important role in diabetic retinopathy. The disease demonstrates both fundamental functions of VEGF, increased permeability and vascular proliferation. Pathologic angiogenesis in proliferative diabetic retinopathy is the major cause of irreversible vision loss in the disease. The better understanding of angiogenesis and angiogenic stimuli has led to new therapies that are starting to complement standard laser care. Halting vascular proliferation will be a major advance in controlling the disease and its sight threatening complications. However, not even biological modulation through antibodies has resolved the intricate pathogenesis of the disease. As the prevalence of diabetes mellitus increases worldwide, diabetic retinopathy remains a challenge.

\section{REFERENCES}

[1] Congdon, N.; O'Colmain, B.; Klaver, C. C.; Klein, R.; Munoz, B.; Friedman, D. S.; Kempen, J.; Taylor, H. R.; Mitchell, P. Causes and prevalence of visual impairment among adults in the United States. Arch. Ophthalmol., 2004, 122, 477-85.

Klein, R.; Klein, B. E.; Moss, S. E.; Davis, M. D.; DeMets, D. L. The Wisconsin epidemiologic study of diabetic retinopathy. III. Prevalence and risk of diabetic retinopathy when age at diagnosis is 30 or more years. Arch. Ophthalmol., 1984, 102, 527-32.

[3] Klein, R.; Klein, B. E.; Moss, S. E.; Davis, M. D.; DeMets, D. L. The Wisconsin epidemiologic study of diabetic retinopathy. II. Prevalence and risk of diabetic retinopathy when age at diagnosis is less than 30 years. Arch. Ophthalmol., 1984, 102, 520-6.

[4] Klein, R.; Klein, B. E.; Moss, S. E.; Davis, M. D.; DeMets, D. L. The Wisconsin epidemiologic study of diabetic retinopathy. IV. Diabetic macular edema. Ophthalmology, 1984, 91, 1464-74.

[5] Early Treatment Diabetic Retinopathy Study Research Group Early photocoagulation for diabetic retinopathy. ETDRS report number 9. Ophthalmology, 1991, 98, 766-85.

[6] The Diabetes Control and Complications Trial Research Group. The effect of intensive treatment of diabetes on the development and progression of long-term complications in insulin-dependent diabetes mellitus N. Engl. J. Med., 1993, 329, 977-86.

[7] UK Prospective Diabetes Study (UKPDS) Group. Intensive bloodglucose control with sulphonylureas or insulin compared with conventional treatment and risk of complications in patients with type 2 diabetes (UKPDS 33). Lancet, 1998, 352, 837-53.

[8] Smiddy, W. E.; Flynn, H. W. Jr. Vitrectomy in the management of diabetic retinopathy. Surv Ophthalmol, 1999, 43, 491-507.

[9] Bhavsar, A. R. Diabetic retinopathy: the latest in current management. Retina, 2006, 26, S71-9.

[10] Diabetic Retinopathy Clinical Research Netwrok. A randomized trial comparing intravitreal triamcinolone acetonide and focal/grid photocoagulation for diabetic macular edema. Ophthalmology, 2008, 115, 1447-59.

[11] Kaur, C.; Foulds, W. S.; Ling, E. A. Blood-retinal barrier in hypoxic ischaemic conditions: basic concepts, clinical features and management. Prog. Retin. Eye. Res., 2008, 27, 622-47.

[12] Yeoh, J.; Williams, C.; Allen, P.; Buttery, R.; Chiu, D.; Clark, B.; Essex, R.; McCombe, M.; Qureshi, S.; Campbell, W. G. Avastin as an adjunct to vitrectomy in the management of severe proliferative diabetic retinopathy: a prospective case series. Clin. Exp. Ophthalmol., 2008, 36, 449-54.

[13] Arevalo, J. F.; Sanchez, J. G.; Wu, L.; Maia, M.; Alezzandrini, A. A.; Brito, M.; Bonafonte, S.; Lujan, S.; Diaz-Llopis, M.; Restrepo, N.; Rodriguez, F. J.; Udaondo-Mirete, P. Primary intravitreal bevacizumab for diffuse diabetic macular edema: the PanAmerican Collaborative Retina Study Group at 24 months. Ophthalmology, 2009, 116, 1488-97.

[14] Beck, R. W.; Edwards, A. R.; Aiello, L. P.; Bressler, N. M.; Ferris, F.; Glassman, A. R.; Hartnett, E.; Ip, M. S.; Kim, J. E.; Kollman, C. Three-year follow-up of a randomized trial comparing focal/grid photocoagulation and intravitreal triamcinolone for diabetic macular edema. Arch. Ophthalmol., 2009, 127, 245-51.

[15] Cho, W. B.; Oh, S. B.; Moon, J. W.; Kim, H. C. Panretinal photocoagulation combined with intravitreal bevacizumab in highrisk proliferative diabetic retinopathy. Retina, 2009, 29, 516-22.

[16] Davis, M. D.; Sheetz, M. J.; Aiello, L. P.; Milton, R. C.; Danis, R. P.; Zhi, X.; Girach, A.; Jimenez, M. C.; Vignati, L. Effect of ruboxistaurin on the visual acuity decline associated with longstanding diabetic macular edema. Invest. Ophthalmol. Vis. Sci., 2009, 50, 1-4.

[17] Jardeleza, M. S.; Miller, J. W. Review of anti-VEGF therapy in proliferative diabetic retinopathy. Semin. Ophthalmol., 2009, 24, 87-92.

[18] Rodriguez-Fontal, M.; Alfaro, V.; Kerrison, J. B.; Jablon, E. P. Ranibizumab for diabetic retinopathy. Curr. Diabetes. Rev., 2009, $5,47-51$.

[19] Rathmann, W.; Giani, G. Global prevalence of diabetes: estimates for the year 2000 and projections for 2030. Diabetes Care, 2004, $27,2568-9$; author reply 9 .

[20] Zimmer-Galler, I. E.; Zeimer, R. Telemedicine in diabetic retinopathy screening. Int. Ophthalmol. Clin., 2009, 49, 75-86.

[21] Bloomgarden, Z. T. Screening for and managing diabetic retinopathy: current approaches. Am. J. Health. Syst. Pharm., 2007, 64, S8-14.

[22] Chew, E. Y. Screening options for diabetic retinopathy. Curr. Opin. Ophthalmol., 2006, 17, 519-22. 
[23] Wilkinson, C. P.; Ferris, F. L.; Klein, R. E.; Lee, P. P.; Agardh, C. D.; Davis, M.; Dills, D.; Kampik, A.; Pararajasegaram, R.; Verdaguer, J. T. Proposed international clinical diabetic retinopathy and diabetic macular edema disease severity scales. Ophthalmology, 2003, 110, 1677-82.

[24] The Diabetic Retinopathy Study Research Group. Photocoagulation treatment of proliferative diabetic retinopathy. Clinical application of Diabetic Retinopathy Study (DRS) findings, DRS Report Number 8. Ophthalmology, 1981, 88, 583-600.

[25] Crawford, T. N.; Alfaro, D. V.; Kerrison, J. B.; Jablon, E. P. Diabetic retinopathy and angiogenesis. Curr. Diabetes. Rev., 2009, 5, 8-13.

[26] Silva, P. S.; Sun, J. K.; Aiello, L. P. Role of steroids in the management of diabetic macular edema and proliferative diabetic retinopathy. Semin. Ophthalmol., 2009, 24, 93-9.

[27] Singh, A.; Stewart, J. M. Pathophysiology of diabetic macular edema. Int. Ophthalmol. Clin., 2009, 49, 1-11.

[28] Cunha-Vaz, J.; Faria de Abreu, J. R.; Campos, A. J. Early breakdown of the blood-retinal barrier in diabetes. $\mathrm{Br} . \mathrm{J}$. Ophthalmol., 1975, 59, 649-56.

[29] Cunha-Vaz, J. G. Studies on the pathophysiology of diabetic retinopathy. The blood-retinal barrier in diabetes. Diabetes, 1983, 32(Suppl 2), 20-7.

[30] Bhagat, N.; Grigorian, R. A.; Tutela, A.; Zarbin, M. A. Diabetic macular edema: pathogenesis and treatment. Surv. Ophthalmol., 2009, 54, 1-32.

[31] Antcliff, R. J.; Marshall, J. The pathogenesis of edema in diabetic maculopathy. Semin. Ophthalmol., 1999, 14, 223-32.

[32] Aroca, P. R.; Salvat, M.; Fernandez, J.; Mendez, I. Risk factors for diffuse and focal macular edema. J. Diabetes. Complicat., 2004, $18,211-5$

[33] Kroll, P.; Rodrigues, E. B.; Hoerle, S. Pathogenesis and classification of proliferative diabetic vitreoretinopathy. Ophthalmologica, 2007, 221, 78-94.

[34] Kohno, T.; Sorgente, N.; Goodnight, R.; Ryan, S. J. Alterations in the distribution of fibronectin and laminin in the diabetic human eye. Invest. Ophthalmol. Vis. Sci., 1987, 28, 515-21.

[35] Casaroli Marano, R. P.; Preissner, K. T.; Vilaro, S. Fibronectin, laminin, vitronectin and their receptors at newly-formed capillaries in proliferative diabetic retinopathy. Exp. Eye. Res., 1995, 60, 5-17.

[36] Fong, D. S.; Ferris, F. L.; Davis, M. D.; Chew, E. Y. Causes of severe visual loss in the early treatment diabetic retinopathy study: ETDRS report no. 24. Early Treatment Diabetic Retinopathy Study Research Group. Am. J. Ophthalmol., 1999, 127, 137-41.

[37] Wakabayashi, T.; Oshima, Y.; Sakaguchi, H.; Ikuno, Y.; Miki, A.; Gomi, F.; Otori, Y.; Kamei, M.; Kusaka, S.; Tano, Y. Intravitreal bevacizumab to treat iris neovascularization and neovascular glaucoma secondary to ischemic retinal diseases in 41 consecutive cases. Ophthalmology, 2008, 115, 1571-80.

[38] Nabili, S.; Kirkness, C. M. Trans-scleral diode laser cyclophotocoagulation in the treatment of diabetic neovascular glaucoma. Eye, 2004, 18, 352-6.

[39] Yildirim, N.; Yalvac, I. S.; Sahin, A.; Ozer, A.; Bozca, T. A comparative study between diode laser cyclophotocoagulation and the Ahmed glaucoma valve implant in neovascular glaucoma: a long-term follow-up. J. Glaucoma, 2009, 18, 192-6.

[40] Shazly, T. A.; Latina, M. A. Neovascular glaucoma: etiology, diagnosis and prognosis. Semin. Ophthalmol., 2009, 24, 113-21.

[41] Bates, D. O.; Harper, S. J. Regulation of vascular permeability by vascular endothelial growth factors. Vascul. Pharmacol., 2002, 39, 225-37.

[42] Stitt, A. W.; Li, Y. M.; Gardiner, T. A.; Bucala, R.; Archer, D. B.; Vlassara, H. Advanced glycation end products (AGEs) co-localize with AGE receptors in the retinal vasculature of diabetic and of AGE-infused rats. Am. J. Pathol., 1997, 150, 523-31.

[43] Sheetz, M. J.; King, G. L. Molecular understanding of hyperglycemia's adverse effects for diabetic complications. JAMA, 2002, 288, 2579-88

[44] Lu, M.; Kuroki, M.; Amano, S.; Tolentino, M.; Keough, K.; Kim, I.; Bucala, R.; Adamis, A. P. Advanced glycation end products increase retinal vascular endothelial growth factor expression. $J$. Clin. Invest., 1998, 101, 1219-24.

[45] Frank, R. N. Diabetic retinopathy. N. Engl. J. Med., 2004, 350, 4858.

[46] Lum, H.; Roebuck, K. A. Oxidant stress and endothelial cell dysfunction. Am J. Physiol. Cell. Physiol., 2001, 280, C719-41.
[47] Chua, C. C.; Hamdy, R. C.; Chua, B. H. Upregulation of vascular endothelial growth factor by $\mathrm{H} 2 \mathrm{O} 2$ in rat heart endothelial cells. Free. Radic. Biol. Med., 1998, 25, 891-7.

[48] Joussen, A. M.; Fauser, S.; Krohne, T. U.; Lemmen, K. D.; Lang, G. E.; Kirchhof, B. Diabetic retinopathy. Pathophysiology and therapy of hypoxia-induced inflammation. Ophthalmologe, 2003, 100, 363-70.

[49] Kuwabara, T.; Cogan, D. G. Retinal vascular patterns. VI. Mural cells of the retinal capillaries. Arch. Ophthalmol., 1963, 69, 492502 .

[50] Soucek, T.; Cumming, R.; Dargusch, R.; Maher, P.; Schubert, D. The regulation of glucose metabolism by HIF-1 mediates a neuroprotective response to amyloid beta peptide. Neuron, 2003, 39, 43-56.

[51] Costa, C.; Soares, R.; Schmitt, F. Angiogenesis: now and then APMIS, 2004, 112, 402-12.

[52] Senger, D. R.; Connolly, D. T.; Van de Water, L.; Feder, J.; Dvorak, H. F. Purification and NH2-terminal amino acid sequence of guinea pig tumor-secreted vascular permeability factor. Cancer. Res., 1990, 50, 1774-8.

[53] Bhisitkul, R. B. Vascular endothelial growth factor biology: clinical implications for ocular treatments. $\mathrm{Br}$. J. Ophthalmol. 2006, 90, 1542-7.

[54] Aiello, L. P.; Avery, R. L.; Arrigg, P. G.; Keyt, B. A.; Jampel, H. D.; Shah, S. T.; Pasquale, L. R.; Thieme, H.; Iwamoto, M. A.; Park, J. E. Vascular endothelial growth factor in ocular fluid of patients with diabetic retinopathy and other retinal disorders. N. Engl. J. Med., 1994, 331, 1480-7.

[55] Witmer, A. N.; Dai, J.; Weich, H. A.; Vrensen, G. F.; Schlingemann, R. O. Expression of vascular endothelial growth factor receptors 1,2 , and 3 in quiescent endothelia. J. Histochem. Cytochem., 2002, 50, 767-77.

[56] Witmer, A. N.; Blaauwgeers, H. G.; Weich, H. A.; Alitalo, K.; Vrensen, G. F.; Schlingemann, R. O. Altered expression patterns of VEGF receptors in human diabetic retina and in experimental VEGF-induced retinopathy in monkey. Invest. Ophthalmol. Vis. Sci., 2002, 43, 849-57.

[57] Wirostko, B.; Wong, T. Y.; Simo, R. Vascular endothelial growth factor and diabetic complications. Prog. Retin. Eye. Res., 2008, 27, 608-21

[58] Duh, E.; Aiello, L. P. Vascular endothelial growth factor and diabetes: the agonist versus antagonist paradox. Diabetes, 1999, 48, 1899-906.

[59] Amin, R. H.; Frank, R. N.; Kennedy, A.; Eliott, D.; Puklin, J. E.; Abrams, G. W. Vascular endothelial growth factor is present in glial cells of the retina and optic nerve of human subjects with nonproliferative diabetic retinopathy. Invest. Ophthalmol. Vis. Sci., 1997, 38, 36-47.

[60] Ferrara, N. Vascular endothelial growth factor: basic science and clinical progress. Endocr. Rev., 2004, 25, 581-611.

[61] Grisanti, S.; Tatar, O. The role of vascular endothelial growth factor and other endogenous interplayers in age-related macular degeneration. Prog. Retin. Eye. Res., 2008, 27, 372-90.

[62] Miller, J. W. Vascular endothelial growth factor and ocular neovascularization. Am. J. Pathol., 1997, 151, 13-23.

[63] Miller, J. W.; Adamis, A. P.; Aiello, L. P. Vascular endothelial growth factor in ocular neovascularization and proliferative diabetic retinopathy. Diabetes. Metab. Rev., 1997, 13, 37-50.

[64] Antonetti, D. A.; Barber, A. J.; Khin, S.; Lieth, E.; Tarbell, J. M.; Gardner, T. W. Vascular permeability in experimental diabetes is associated with reduced endothelial occludin content: vascular endothelial growth factor decreases occludin in retinal endothelial cells. Penn State Retina Research Group. Diabetes, 1998, 47, 19539.

[65] Kaur, C.; Sivakumar, V.; Yong, Z.; Lu, J.; Foulds, W. S.; Ling, E. A. Blood-retinal barrier disruption and ultrastructural changes in the hypoxic retina in adult rats: the beneficial effect of melatonin administration. J. Pathol., 2007, 212, 429-39.

[66] Tolentino, M. J.; McLeod, D. S.; Taomoto, M.; Otsuji, T.; Adamis, A. P.; Lutty, G. A. Pathologic features of vascular endothelial growth factor-induced retinopathy in the nonhuman primate. Am. J. Ophthalmol., 2002, 133, 373-85.

[67] Adamis, A. P.; Shima, D. T.; Tolentino, M. J.; Gragoudas, E. S.; Ferrara, N.; Folkman, J.; D'Amore, P. A.; Miller, J. W. Inhibition of vascular endothelial growth factor prevents retinal ischemia- 
associated iris neovascularization in a nonhuman primate. Arch. Ophthalmol., 1996, 114, 66-71.

[68] Tolentino, M. J.; Miller, J. W.; Gragoudas, E. S.; Chatzistefanou, K.; Ferrara, N.; Adamis, A. P. Vascular endothelial growth factor is sufficient to produce iris neovascularization and neovascular glaucoma in a nonhuman primate. Arch. Ophthalmol., 1996, 114, 964-70.

[69] Tolentino, M. J.; Miller, J. W.; Gragoudas, E. S.; Jakobiec, F. A.; Flynn, E.; Chatzistefanou, K.; Ferrara, N.; Adamis, A. P. Intravitreous injections of vascular endothelial growth factor produce retinal ischemia and microangiopathy in an adult primate. Ophthalmology, 1996, 103, 1820-8.

[70] Patel, J. I.; Tombran-Tink, J.; Hykin, P. G.; Gregor, Z. J.; Cree, I. A. Vitreous and aqueous concentrations of proangiogenic, antiangiogenic factors and other cytokines in diabetic retinopathy patients with macular edema: Implications for structural differences in macular profiles. Exp. Eye. Res., 2006, 82, 798-806.

[71] Dawson, D. W.; Volpert, O. V.; Gillis, P.; Crawford, S. E.; Xu, H.; Benedict, W.; Bouck, N. P. Pigment epithelium-derived factor: a potent inhibitor of angiogenesis. Science, 1999, 285, 245-8.

[72] Elayappan, B.; Ravinarayannan, H.; Sardar Pasha, S. P.; Lee, K. J.; Gurunathan, S. PEDF inhibits VEGF- and EPO- induced angiogenesis in retinal endothelial cells through interruption of PI3K/Akt phosphorylation. Angiogenesis, 2009, [Epub ahead of print]

[73] Duh, E. J.; Yang, H. S.; Suzuma, I.; Miyagi, M.; Youngman, E.; Mori, K.; Katai, M.; Yan, L.; Suzuma, K.; West, K.; Davarya, S.; Tong, P.; Gehlbach, P.; Pearlman, J.; Crabb, J. W.; Aiello, L. P.; Campochiaro, P. A.; Zack, D. J. Pigment epithelium-derived factor suppresses ischemia-induced retinal neovascularization and VEGFinduced migration and growth. Invest. Ophthalmol. Vis. Sci., 2002, $43,821-9$.

[74] Adamis, A. P.; Berman, A. J. Immunological mechanisms in the pathogenesis of diabetic retinopathy. Semin. Immunopathol., 2008, 30, 65-84.

[75] Joussen, A. M.; Poulaki, V.; Qin, W.; Kirchhof, B.; Mitsiades, N.; Wiegand, S. J.; Rudge, J.; Yancopoulos, G. D.; Adamis, A. P. Retinal vascular endothelial growth factor induces intercellular adhesion molecule-1 and endothelial nitric oxide synthase expression and initiates early diabetic retinal leukocyte adhesion in vivo. Am. J. Pathol., 2002, 160, 501-9.

[76] Muller, W. A. Mechanisms of transendothelial migration of leukocytes. Circ. Res., 2009, 105, 223-30.

[77] McLeod, D. S.; Lefer, D. J.; Merges, C.; Lutty, G. A. Enhanced expression of intracellular adhesion molecule-1 and P-selectin in the diabetic human retina and choroid. Am. J. Pathol., 1995, 147, 642-53.

[78] Joussen, A. M.; Murata, T.; Tsujikawa, A.; Kirchhof, B.; Bursell, S. E.; Adamis, A. P. Leukocyte-mediated endothelial cell injury and death in the diabetic retina. Am. J. Pathol., 2001, 158, 147-52.

[79] Steinberg, S. F. Structural basis of protein kinase C isoform function. Physiol. Rev., 2008, 88, 1341-78.

[80] Aiello, L. P.; Bursell, S. E.; Clermont, A.; Duh, E.; Ishii, H.; Takagi, C.; Mori, F.; Ciulla, T. A.; Ways, K.; Jirousek, M.; Smith, L. E.; King, G. L. Vascular endothelial growth factor-induced retinal permeability is mediated by protein kinase $\mathrm{C}$ in vivo and suppressed by an orally effective beta-isoform-selective inhibitor. Diabetes, 1997, 46, 1473-80.

[81] Khan, Z. A.; Chakrabarti, S. Cellular signaling and potential new treatment targets in diabetic retinopathy. Exp. Diabetes. Res., 2007, 2007, 31867.

[82] Fong, D. S.; Gottlieb, J.; Ferris, F. L.; Klein, R. Understanding the value of diabetic retinopathy screening. Arch. Ophthalmol., 2001, 119, 758-60.

[83] Takagi, H.; Watanabe, D.; Suzuma, K.; Kurimoto, M.; Suzuma, I.; Ohashi, H.; Ojima, T.; Murakami, T. Novel role of erythropoietin in proliferative diabetic retinopathy. Diabetes. Res. Clin. Pract., 2007, 77(Suppl 1), S62-4.

[84] Garci-Arumi, J.; Fonollosa, A.; Macia, C.; Hernandez, C.; Martinez-Castillo, V.; Boixadera, A.; Zapata, M. A.; Simo, R. Vitreous levels of erythropoietin in patients with macular oedema secondary to retinal vein occlusions: a comparative study with diabetic macular oedema. Eye, 2009, 23, 1066-71.

[85] Watanabe, D.; Suzuma, K.; Matsui, S.; Kurimoto, M.; Kiryu, J.; Kita, M.; Suzuma, I.; Ohashi, H.; Ojima, T.; Murakami, T.; Kobayashi, T.; Masuda, S.; Nagao, M.; Yoshimura, N.; Takagi, H.
Erythropoietin as a retinal angiogenic factor in proliferative diabetic retinopathy. N. Engl. J. Med., 2005, 353, 782-92.

[86] Diskin, C. J. Erythropoietin and retinopathy: the beginning of an understanding. Br. J. Ophthalmol., 2008, 92, 574.

[87] Diskin, C. J.; Stokes, T. J.; Dansby, L. M.; Radcliff, L.; Carter, T. B. A hypothesis: can erythropoietin administration affect the severity of retinopathy in diabetic patients with renal failure? Am. J. Med. Sci., 2007, 334, 260-4.

[88] Zhang, J.; Wu, Y.; Jin, Y.; Ji, F.; Sinclair, S. H.; Luo, Y.; Xu, G.; Lu, L.; Dai, W.; Yanoff, M.; Li, W.; Xu, G. T. Intravitreal injection of erythropoietin protects both retinal vascular and neuronal cells in early diabetes. Invest. Ophthalmol. Vis. Sci., 2008, 49, 732-42.

[89] White, N. H.; Sun, W.; Cleary, P. A.; Danis, R. P.; Davis, M. D.; Hainsworth, D. P.; Hubbard, L. D.; Lachin, J. M.; Nathan, D. M. Prolonged effect of intensive therapy on the risk of retinopathy complications in patients with type 1 diabetes mellitus: 10 years after the Diabetes Control and Complications Trial. Arch. Ophthalmol., 2008, 126, 1707-15.

[90] Shah, C. A. Diabetic retinopathy: A comprehensive review. Indian. J. Med. Sci., 2008, 62, 500-19.

[91] Matthews, D. R.; Stratton, I. M.; Aldington, S. J.; Holman, R. R.; Kohner, E. M. Risks of progression of retinopathy and vision loss related to tight blood pressure control in type 2 diabetes mellitus: UKPDS 69. Arch. Ophthalmol., 2004, 122, 1631-40.

[92] UK Prospective Diabetes Study Group. Tight blood pressure control and risk of macrovascular and microvascular complications in type 2 diabetes: UKPDS 38. BMJ, 1998, 317, 703-13.

[93] Schrier, R. W.; Estacio, R. O.; Esler, A.; Mehler, P. Effects of aggressive blood pressure control in normotensive type 2 diabetic patients on albuminuria, retinopathy and strokes. Kidney Int, 2002, 61, 1086-97.

[94] Chew, E. Y.; Klein, M. L.; Ferris, F. L.; Remaley, N. A.; Murphy, R. P.; Chantry, K.; Hoogwerf, B. J.; Miller, D. Association of elevated serum lipid levels with retinal hard exudate in diabetic retinopathy. Early Treatment Diabetic Retinopathy Study (ETDRS) Report 22. Arch. Ophthalmol., 1996, 114, 1079-84.

[95] Lyons, T. J.; Jenkins, A. J.; Zheng, D.; Lackland, D. T.; McGee, D.; Garvey, W. T.; Klein, R. L. Diabetic retinopathy and serum lipoprotein subclasses in the DCCT/EDIC cohort. Invest. Ophthalmol. Vis. Sci., 2004, 45, 910-8.

[96] Keech, A. C.; Mitchell, P.; Summanen, P. A.; O'Day, J.; Davis, T. M.; Moffitt, M. S.; Taskinen, M. R.; Simes, R. J.; Tse, D.; Williamson, E.; Merrifield, A.; Laatikainen, L. T.; d'Emden, M. C.; Crimet, D. C.; O'Connell, R. L.; Colman, P. G. Effect of fenofibrate on the need for laser treatment for diabetic retinopathy (FIELD study): a randomised controlled trial. Lancet, 2007, 370, 1687-97.

[97] Bergerhoff, K.; Clar, C.; Richter, B. Aspirin in diabetic retinopathy. A systematic review. Endocrinol. Metab. Clin. North. Am., 2002, 31, 779-93.

[98] Neubauer, A. S.; Ulbig, M. W. Laser treatment in diabetic retinopathy. Ophthalmologica, 2007, 221, 95-102.

[99] Mohamed, Q.; Gillies, M. C.; Wong, T. Y. Management of diabetic retinopathy: a systematic review. JAMA, 2007, 298, 902-16.

[100] Flynn, H. W., Jr.; Chew, E. Y.; Simons, B. D.; Barton, F. B.; Remaley, N. A.; Ferris, F. L. Pars plana vitrectomy in the Early Treatment Diabetic Retinopathy Study. ETDRS report number 17. The Early Treatment Diabetic Retinopathy Study Research Group. Ophthalmology, 1992, 99, 1351-7.

[101] Huang, Y. H.; Yeh, P. T.; Chen, M. S.; Yang, C. H.; Yang, C. M. Intravitreal bevacizumab and panretinal photocoagulation for proliferative diabetic retinopathy associated with vitreous hemorrhage. Retina, 2009, 29, 1134-40.

[102] Gragoudas, E. S.; Adamis, A. P.; Cunningham, E. T., Jr.; Feinsod, M.; Guyer, D. R. Pegaptanib for neovascular age-related macular degeneration. N. Engl. J. Med., 2004, 351, 2805-16.

[103] Krzystolik, M. G.; Filippopoulos, T.; Ducharme, J. F.; Loewenstein, J. I. Pegaptanib as an adjunctive treatment for complicated neovascular diabetic retinopathy. Arch. Ophthalmol., 2006, 124, 920-1.

[104] Cunningham, E. T., Jr.; Adamis, A. P.; Altaweel, M.; Aiello, L. P.; Bressler, N. M.; D'Amico, D. J.; Goldbaum, M.; Guyer, D. R.; Katz, B.; Patel, M.; Schwartz, S. D. A phase II randomized doublemasked trial of pegaptanib, an anti-vascular endothelial growth factor aptamer, for diabetic macular edema. Ophthalmology, 2005, $112,1747-57$. 
[105] Rosenfeld, P. J.; Brown, D. M.; Heier, J. S.; Boyer, D. S.; Kaiser, P. K.; Chung, C. Y.; Kim, R. Y. Ranibizumab for neovascular agerelated macular degeneration. N. Engl. J. Med., 2006, 355, 141931.

[106] Brown, D. M.; Kaiser, P. K.; Michels, M.; Soubrane, G.; Heier, J. S.; Kim, R. Y.; Sy, J. P.; Schneider, S. Ranibizumab versus verteporfin for neovascular age-related macular degeneration. $N$. Engl. J. Med., 2006, 355, 1432-44.

[107] Chun, D. W.; Heier, J. S.; Topping, T. M.; Duker, J. S.; Bankert, J. M. A pilot study of multiple intravitreal injections of ranibizumab in patients with center-involving clinically significant diabetic macular edema. Ophthalmology, 2006, 113, 1706-12.

[108] Querques, G.; Bux, A. V.; Martinelli, D.; Iaculli, C.; Del Curatolo, M. V.; Noci, N. D. Short-Term Fluctuation of Diabetic Macular Edema after Intravitreal Ranibizumab Injection. Retina, 2009, [Epub ahead of print].

[109] Rosenfeld, P. J.; Moshfeghi, A. A.; Puliafito, C. A. Optical coherence tomography findings after an intravitreal injection of bevacizumab (avastin) for neovascular age-related macular degeneration. Ophthalmic. Surg. Lasers Imaging., 2005, 36, 331-5.

[110] Aisenbrey, S.; Ziemssen, F.; Volker, M.; Gelisken, F.; Szurman, P.; Jaissle, G.; Grisanti, S.; Bartz-Schmidt, K. U. Intravitreal bevacizumab (Avastin) for occult choroidal neovascularization in age-related macular degeneration. Graefes. Arch. Clin. Exp. Ophthalmol., 2007, 245, 941-8.

[111] Minnella, A. M.; Savastano, C. M.; Ziccardi, L.; Scupola, A.; Falsini, B.; Balestrazzi, E. Intravitreal bevacizumab (Avastin) in proliferative diabetic retinopathy. Acta. Ophthalmol., 2008, 86, 683-7.

[112] Avery, R. L.; Pearlman, J.; Pieramici, D. J.; Rabena, M. D.; Castellarin, A. A.; Nasir, M. A.; Giust, M. J.; Wendel, R.; Patel, A. Intravitreal bevacizumab (Avastin) in the treatment of proliferative diabetic retinopathy. Ophthalmology, 2006, 113, 1695-705.

[113] Arevalo, J. F.; Garcia-Amaris, R. A. Intravitreal bevacizumab for diabetic retinopathy. Curr. Diabetes. Rev., 2009, 5, 39-46.

[114] Spaide, R. F.; Fisher, Y. L. Intravitreal bevacizumab (Avastin) treatment of proliferative diabetic retinopathy complicated by vitreous hemorrhage. Retina, 2006, 26, 275-8.

[115] Carneiro, A.; Falcao, M.; Azevedo, I.; Falcao Reis, F.; Soares, R. Multiple effects of bevacizumab in angiogenesis: implications for its use in age-related macular degeneration. Acta. Ophthalmol., 2009, 87, 517-23.

[116] Carneiro, A.; Falcao, M.; Pirraco, A.; Milheiro-Oliveira, P.; FalcaoReis, F.; Soares, R. Comparative effects of bevacizumab, ranibizumab and pegaptanib at intravitreal dose range on endothelial cells. Exp. Eye Res., 2009, 88, 522-7.

[117] Wu, L.; Martinez-Castellanos, M. A.; Quiroz-Mercado, H.; Arevalo, J. F.; Berrocal, M. H.; Farah, M. E.; Maia, M.; Roca, J. A.; Rodriguez, F. J. Twelve-month safety of intravitreal injections of bevacizumab (Avastin): results of the Pan-American Collaborative Retina Study Group (PACORES). Graefes. Arch. Clin. Exp. Ophthalmol., 2008, 246, 81-7.

[118] Mansoor, S.; Kuppermann, B. D.; Kenney, M. C. Intraocular sustained-release delivery systems for triamcinolone acetonide. Pharm. Res., 2009, 26, 770-84.

[119] Jermak, C. M.; Dellacroce, J. T.; Heffez, J.; Peyman, G. A. Triamcinolone acetonide in ocular therapeutics. Surv. Ophthalmol., 2007, 52, 503-22.

[120] Yilmaz, T.; Weaver, C. D.; Gallagher, M. J.; Cordero-Coma, M.; Cervantes-Castaneda, R. A.; Klisovic, D.; Lavaque, A. J.; Larson, R. J. Intravitreal triamcinolone acetonide injection for treatment of refractory diabetic macular edema: a systematic review. Ophthalmology, 2009, 116, 902-11; quiz 12-3.

[121] Aiello, L. P.; Davis, M. D.; Girach, A.; Kles, K. A.; Milton, R. C.; Sheetz, M. J.; Vignati, L.; Zhi, X. E. Effect of ruboxistaurin on visual loss in patients with diabetic retinopathy. Ophthalmology, 2006, 113, 2221-30.

[122] Smiddy, W. E.; Feuer, W.; Irvine, W. D.; Flynn, H. W., Jr.; Blankenship, G. W. Vitrectomy for complications of proliferative diabetic retinopathy. Functional outcomes. Ophthalmology, 1995, 102, 1688-95.

[123] Gunduz, K.; Bakri, S. J. Management of proliferative diabetic retinopathy. Compr. Ophthalmol. Update., 2007, 8, 245-56.

[124] Figueroa, M. S.; Contreras, I.; Noval, S. Anti-angiogenic drugs as an adjunctive therapy in the surgical treatment of diabetic retinopathy. Curr. Diabetes. Rev., 2009, 5, 52-6.

[125] Hartley, K. L.; Smiddy, W. E.; Flynn, H. W., Jr.; Murray, T. G. Pars plana vitrectomy with internal limiting membrane peeling for diabetic macular edema. Retina, 2008, 28, 410-9.

(C) Falcão et al.; Licensee Bentham Open.

This is an open access article licensed under the terms of the Creative Commons Attribution Non-Commercial License (http://creativecommons.org/licenses/by-nc/3.0/) which permits unrestricted, non-commercial use, distribution and reproduction in any medium, provided the work is properly cited. 